\title{
EL FIN DEL SOCIALISMO SOVIÉTICO, LA REVOLUCIÓN CUBANA Y LA IZQUIERDA LATINOAMERICANA: LA HISTORIA DE UNA DOBLE DERROTA*
}

\author{
Rafael Pedemonte \\ Universidad de Gante
}

\begin{abstract}
RESUMEN: La caída de la Unión Soviética generó un proceso inevitable de reevaluación ideológica en el seno de los partidos comunistas de América Latina, proceso que fue particularmente dramático en el caso cubano. Luego de que, a comienzos de la década de 1970, la administración castrista reforzara sus lazos con el Kremlin y recibiera a cambio una asistencia esencial para la supervivencia de su proyecto socialista, las reformas de la era Gorbachov llevaron a la dirigencia cubana a iniciar un profundo proceso de "rectificación", que significó reapropiarse aceleradamente de las referencias locales de la revolución (Martí, Che Guevara), en desmedro de los "clásicos" del marxismo ortodoxo. Una reescritura similar llevaron adelante otras organizaciones tradicionalmente fieles a Moscú, como el Partido Comunista de Chile.

Palabras Clave: Unión Soviética, comunismo, Revolución Cubana, Mijaíl Gorbachov, Nueva Izquierda Latinoamericana.
\end{abstract}

Rafael Pedemonte. Doctor en historia por la Universidad de París 1 PanthéonSorbonne y la Pontificia Universidad Católica de Chile. Investigador en el Departamento de Historia de la Universidad de Gante, Bélgica. Email: rafaelpedemonte@, gmail.com.

* Este ensayo fue preparado con ocasión del seminario "La Revolución Rusa y su influencia en América Latina y Chile", celebrado en el Centro de Estudios Públicos, el 17 de octubre de 2017. 


\title{
THE END OF SOVIET SOCIALISM, THE CUBAN REVOLUTION AND THE LATIN AMERICAN LEFT: THE HISTORY OF A TWOFOLD DEFEAT
}

\begin{abstract}
The fall of the Soviet Union inevitably led to ideological reassessment in the communist parties of Latin America, a process that was particularly dramatic in Cuba. After the Castro administration strengthened its ties to the Kremlin in the early 1970s, receiving in return assistance essential to the survival of its socialist project, the Gorbachev era reforms led the Cuban leadership to begin a far-reaching "correction" involving the rapid reappropriation of local revolutionary emblems (Marti, Che Guevara) at the expense of the "classic" ones of orthodox Marxism. The past was similarly revisited by other organizations traditionally loyal to Moscow, such as the Communist Party of Chile.
\end{abstract}

Keywords: Soviet Union, communism, Cuban Revolution, Mikhail Gorbachev, Latin American New Left.

\section{¡NO MÁS CUBAS EN AMÉRICA LATINA!}

$\mathrm{L}$ uego de una fase de serias discrepancias estratégicas y políticas entre la Unión Soviética y la directiva revolucionaria cubana, el fin de la década de 1960 inauguró un proceso de convergencias crecientes, dando paso a la consolidación de una sólida alianza Cuba-URSS. El año 1971 constituyó en este proceso una fecha clave, que inició un periodo que se ha dado a conocer como el Quinquenio Gris (Fornet 2007), y que, mediante un sinnúmero de síntomas elocuentes, hizo evidente la inserción definitiva de La Habana en la esfera geopolítica dominada por el Kremlin. Sacrificando considerables recursos para proteger a la "Isla de la libertad" y favorecer de paso su estabilidad económica, Moscú optó finalmente, no sin vacilaciones, por preservar la fidelidad de los "compañeros" cubanos para así poder exhibir un triunfo único en la historia de la Guerra Fría: disponer de un aliado de peso en el seno mismo de la "zona de influencia" (Kaufman 1976) del "enemigo norteamericano”. Este Quinquenio Gris (1971-1976), ${ }^{1}$ denominación recurrente que pretende dar cuenta de las restricciones impuestas por la adopción de un

${ }^{1}$ Otros, como el escritor cubano Pablo Armando Fernández o el poeta César López, prefieren hablar de "Decenio Negro" (Fernández 2012, 152). 
modelo cultural e ideológico inspirado en el esquema de la URSS, vio surgir una serie de signos que contribuyeron a afianzar la amistad cubano-soviética: La Habana ingresó al Comecon (Consejo de Ayuda Mutua Económica), entidad de cooperación económica del mundo socialista, en 1972; los acuerdos de cooperación se multiplicaron y diversificaron, haciéndose cada vez más generosos en beneficio del gobierno castrista (Latrèche 2011, 132); Leonid Brezhnev se convirtió en el primer líder del Partido Comunista de la URSS (PCUS) en visitar América Latina cuando, en 1974, desembarcó en Cuba; el idioma ruso se impuso como una disciplina obligatoria en los programas escolares, mientras que los cursos para aprender la lengua de Tolstoi se difundían mediante programas radiales y televisivos (Cino Colina 2010, 24-27); se tendió a adoptar en el ámbito cultural códigos estéticos normativos similares a los restrictivos principios del "realismo socialista", conllevando a la marginalización de los artistas más vanguardistas y menos inclinados a la exaltación ideológica, como Antón Arrufat, Pablo Armando Fernández, José Lezama Lima y un largo etcétera. En fin, a partir de ese momento ya no cabía duda de que Cuba se había convertido en un devoto representante del campo liderado por la URSS. ${ }^{2}$

En lo que concierne a la URSS, desde una óptica latinoamericana, las autoridades parecían por el momento conformarse con su imponente presencia en la isla caribeña, manteniendo una visible prudencia en el resto del continente, y entablando incluso estrechas vinculaciones con regímenes abiertamente anticomunistas. Mucho se ha dicho ya sobre la actitud retraída con que Moscú siguió los eventos del Chile de Salvador Allende (1970-1973). Temiendo intensificar las tensiones con los Esta-

${ }^{2}$ Autores como Piero Gleijeses (2002) o Antoni Kapcia (2009) intentan, sin embargo, relativizar la fidelidad del aliado cubano, invocando sobre todo la autonomía con la que La Habana actuó en las luchas de independencia africanas, especialmente en Angola, donde los combatientes cubanos alcanzaron la inédita cifra de casi 500 mil en el periodo 1975-1989. Es cierto que en muchos aspectos el gobierno de Fidel Castro mantuvo una postura relativamente autónoma, pero lo mismo podría decirse de otros "países satélites", como Polonia y la Rumania de Ceauşescu. El tono laudatorio con que los dirigentes cubanos se referían a la URSS, así como el establecimiento de un sistema institucional cada vez más parecido al dominante en el mundo del Este demuestran que - aunque sin duda a regañadientes- el castrismo había aceptado el liderazgo soviético dentro del sistema socialista mundial, lo que contrastaba nítidamente con los constantes desafíos de los cubanos a la autoridad de la URSS, durante los años 60. 
dos Unidos en tiempos de la détente y evitando volver a comprometerse económicamente con un país distante, ${ }^{3}$ las autoridades soviéticas optaron - a pesar de las presiones de los dirigentes chilenos, incluido del propio Presidente Allende, quien viajó a la URSS en diciembre de 1972 para negociar, sin éxito, el otorgamiento de una serie de créditos- por limitar la asistencia destinada al proyecto de la Unidad Popular. Consolidada la entente con Cuba, la URSS ya no tenía como prioridad seguir demostrando la aplicabilidad universal de su modelo mediante la multiplicación de aliados latinoamericanos, políticamente inestables y geográficamente alejados. Incluso el triunfo de la Revolución Sandinista en 1979 — potente reactivación del sueño revolucionario en América Latina, luego de una larga fase de derrotas dramáticas para las guerrillas del subcontinente - fue recibido con discreción. La victoria de los revolucionarios nicaragüenses sorprendió a los dirigentes moscovitas, quienes, basados en consideraciones pragmáticas, desarrollaron a partir de 1979 una política de asistencia (si bien en ningún caso marginal) menos decisiva de lo esperado (Paszyn 2000, 8-55).

Mientras la realpolitik se imponía a la hora de definir una estrategia con los gobiernos latinoamericanos afines, la URSS no tuvo escrúpulos en solidificar sus lazos con gobiernos autoritarios y enemigos de las ideas de izquierda, como las dictaduras en Argentina (1976-1983) y en Brasil (1964-1985). El caso de las relaciones con Buenos Aires es llamativo. A pesar de la retórica anticomunista de Jorge Rafael Videla y de sus seguidores, los soviéticos entablaron con la Casa Rosada estrechas relaciones en el ámbito comercial. En 1981, por ejemplo, la URSS absorbió 33,7 por ciento de las exportaciones argentinas en respuesta al embargo cerealero impuesto por los Estados Unidos a raíz de la invasión a Afganistán (1979). El afianzamiento de las vinculaciones económicas fue también acompañado de una suerte de "alianza diplomática", evidente cuando en 1977 los representantes soviéticos ante la Comisión de Derechos Humanos de la ONU rechazaron un proyecto destinado a autorizar una encuesta en territorio argentino, o cuando en 1982 Moscú

${ }^{3}$ De visita en Moscú, el secretario general del Partido Socialista de Chile, Carlos Altamirano, recibió una respuesta incontrarrestable a sus solicitudes de asistencia al gobierno de Allende. Para justificar su circunspección, Leonid Brezhnev le habría dicho al delegado chileno: "Mire, considere usted que Chile es el país más distante de la URSS, que no hay otro país que quede tan lejos como el de ustedes" (Politzer 1990, 112). 
entregó su apoyo irrestricto a Argentina en el contexto de la Guerra de las Malvinas (Vacs 1984, 78-86).

En este contexto, el pragmatismo de la URSS, sumado a la represión creciente en el Cono Sur (Chile, Perú, Uruguay, Brasil, Paraguay) contra los militantes comunistas defensores del modelo del Este, marcó una era de retirada progresiva de las influencias ideológicas de la URSS en América Latina. Cuba, por cierto, seguía representando durante los años setenta una notable excepción. El inicio de la década de 1980 tampoco dejó entrever una eventual atenuación de los lazos con Moscú, aunque la progresiva introducción de tendencias reformistas en el seno del Partido Comunista de la URSS (PCUS) y la desaparición física de la "vieja guardia" soviética (Yuri Andropov, Konstantín Chernenko) anunciaron una reestructuración de las prioridades internacionales del Kremlin. Este nuevo cuadro - determinado por los aires de cambio instalados por el nuevo jefe del PCUS, Mijaíl Gorbachov- afectaría inevitablemente la solidez de la asociación con el gobierno castrista, una tendencia perceptible desde mucho antes de que el "coloso del Este" se derrumbara. Como veremos ahora, la Cuba socialista, a pesar de los incontables sacrificios materiales generados por la desaparición del "hermano mayor", desmintió todos los pronósticos y logró sobrevivir en un contexto hostil. Pero la resistencia del gobierno sin Moscú implicó necesariamente la búsqueda de una nueva y más autónoma legitimidad ideológica, basada en una suerte de renegación de la antigua adscripción al "socialismo ortodoxo" encarnado por la superpotencia ausente.

\section{MIJAÍL GORBACHOV Y EL COMIENZO DEL FIN}

En términos generales, el programa internacional de Gorbachov se encontraba menos anclado en factores ideológicos, lo que llevó al interior del PCUS a un cuestionamiento de las alianzas tradicionales, sobre todo de las más onerosas, en función de una postura de mayor pragmatismo. Los propios expertos soviéticos desvelaban sin tapujos las consecuencias de la postura de la nueva administración, anunciando tiempos difíciles para los tradicionales aliados internacionales y, en particular, para el gobierno cubano. Siguiendo a Karen Brutents, consejero influyente del círculo de internacionalistas de Gorbachov, la URSS decidió "desterrar" de sus prácticas diplomáticas "el mesianismo ideológico, la 
confrontación global con los Estados Unidos y sus aliados, el armamentismo excesivo" (Brutents 1992, 74). Ante esta perspectiva, la inquietud de los dirigentes de la isla quedó dramáticamente ejemplificada en el elocuente discurso de Fidel Castro con ocasión de la visita de Gorbachov a Cuba en 1989, uno de los últimos signos de esperanza para los cubanos inquietos: "Lo menos que podemos expresar en este día, desde lo más profundo de nuestros corazones, es nuestro deseo de éxito al compañero Gorbachov (...) porque ese éxito no sólo lo deseamos, sino que lo necesitamos" (Castro 1989). En efecto, pocos países en el orbe sufrieron más que Cuba la paulatina retirada de los soviéticos.

Desde la fecha de la asunción del nuevo líder del PCUS (1985) y de la puesta en práctica de la Glásnost, una política que implicaba un mayor acceso público a información antes catalogada como confidencial, las reticencias hacia el voluntarismo internacional se agudizaron. Los gastos militares en el extranjero constituían uno de aquellos secretos meticulosamente conservados hasta que, en 1986, el Politburó reveló, ante la consternación de muchos, los datos oficiales: el costo anual de la asistencia militar a Cuba llegaba a 25 millones de rublos, cifra sólo superada por Vietnam (40 millones) y más de cuatro veces más elevada que el desembolso destinado a Siria (Zubok 2007, 299). En una era de crisis económica, cuando muchos habitantes soviéticos experimentaban a diario estrecheces de todo tipo, le difusión de esta información no hizo más que exacerbar los ánimos, empujando a muchos a exigir el cese de los "subsidios". La "cuestión cubana", en particular, generó entre 1985 y 1991 — año del inesperado derrumbe de la URSS - un arduo debate interno, siendo incluso un tema de divergencia en el seno mismo de la administración. El medio intelectual también permaneció dividido. Mientras que destacados comentaristas como Víctor Volsky y Sergo Mikoyan, ${ }^{4}$ entusiastas observadores de los procesos políticos en América Latina, integraban el "lobby cubano" en Moscú (Pavlov 1994, 177), otros simplemente exigían la interrupción inmedia-

${ }^{4}$ El padre de Sergo Mikoyan, Anastás Mikoyan, una de las figuras políticas más relevantes de la historia de la URSS, fue quien lideró la primera misión oficial soviética a Cuba en 1960, efectuada con el objeto de evaluar la disposición de las autoridades revolucionarias y, eventualmente, definir un programa de asistencia con el gobierno castrista. Sus impresiones, transmitidas poco después de su estadía a Nikita Jrushchov, fueron muy positivas, influyendo así de manera decisiva en el desarrollo de las relaciones cubano-soviéticas (Khrouchtchev 1971, 464). 
ta de la ayuda hacia la Revolución Cubana, argumentando, por ejemplo, que no era posible mantener la solidaridad con "el último estaliniano", en referencia a Fidel Castro (Mikoyan 1992, 121).

Si bien Mijaíl Gorbachov nunca manifestó una real voluntad de interrumpir drásticamente la ayuda hacia el gobierno de los hermanos Castro, a quienes parece haber estimado en lo personal, era evidente que su renovado posicionamiento internacional daría paso a una redefinición de la postura hacia América Latina. Como bien lo subraya uno de los más minuciosos analistas de la política exterior soviética, Vladislav Zubok (gracias a un impresionante arsenal de fuentes rusas), la nueva concepción de "lo global" conduciría inevitablemente al debilitamiento de los antiguos dogmas ideológicos y a su reemplazo por una postura menos hostil hacia Occidente. De esta forma, las autoridades del Kremlin comenzaron a cuestionarse la pertinencia de conservar un discurso inflexible y desarrollaron uno nuevo, basado en el abandono de la retórica bipolar heredera de los tiempos estalinianos y en la renuncia de las apuestas riesgosas destinadas a debilitar la influencia del modelo norteamericano (Zubok 2007, 278-287). La defensa de Cuba desde los distantes años 60, que pudo incluso haber provocado un conflicto de consecuencias apocalípticas (la crisis de los misiles en 1962), obedecía en definitiva a una lógica que el equipo de Gorbachov ya no estaba dispuesto a mantener.

No cabe duda de que cuando Jrushchov tomó la decisión de embarcarse en una alianza costosa con una isla de no más de siete millones de habitantes ubicada a cerca de 100 kilómetros del "enemigo del norte", una de sus intenciones primordiales era erosionar la dominación estadounidense en su territorio de influencia. Este compromiso - que no podría explicarse sin tomar en consideración la personalidad vehemente e impulsiva de Jrushchov, así como su convicción apasionada de que nada podría detener el triunfo final de la revolución mundial (Taubman 2003, 640) - resulta aún más sorprendente si notamos que las autoridades castristas no fueron para nada unos aliados dóciles. Por el contrario, durante gran parte de los años 60, Fidel Castro, y en particular el argentino Ernesto Che Guevara, no cesaron de criticar la política de Moscú, profesando un militantismo revolucionario más radical, que se oponía a la política soviética de acercamiento internacional. En efecto, mientras los líderes cubanos alentaban las acciones de las guerrillas en el continente latinoamericano, el Kremlin prefería construir redes diplomáticas 
con gobiernos "progresistas" (entre ellos, la "Revolución en Libertad" de Eduardo Frei en Chile) y no verse involucrado en tentativas de "exportar la revolución".

Si a pesar de todos aquellos obstáculos Moscú estaba dispuesto a defender el "primer territorio libre de América" era porque la URSS seguía actuando bajo la óptica de un mundo en constante confrontación con el capitalismo. Por ende, valía la pena hacer sacrificios o idear peligrosos emplazamientos para atacar a los Estados Unidos (ante la imposibilidad de un enfrentamiento directo) mediante "golpes geopolíticos", como la conversión de Cuba en un país socialista. A la luz de lo que nos revela el historiador Vladislav Zubok, podemos observar que este estado de ánimo ya no se hallaba presente en la visión estratégica de la URSS gorbachoviana, lo que necesariamente acarrearía una reevaluación de la amplia asistencia otorgada a La Habana y elevaría las voces de quienes ya no veían la necesidad de seguir sosteniendo a un partner lejano y oneroso. Veremos ahora que, ante los signos que anunciaban una nueva era, Fidel Castro, con su agudo instinto político, midió tempranamente las consecuencias que el new thinking soviético generaría en su propio país y comenzó a prepararse para que la "liberalización" del "hermano mayor" no contagiara los espíritus de la dirección cubana.

\section{CUBA ANTE LA CRISIS SOVIÉTICA: "SOCIALISMO O MUERTE"}

En un diálogo de enero 1989 con su amigo Gabriel García Márquez, observador más bien optimista de la renovación ideológica iniciada en la URSS, Fidel Castro le manifestó al escritor colombiano sus aprensiones sobre lo que estaba sucediendo en el campo socialista: "No estoy en contra de los principios de la Perestroika (...), pero es una política muy riesgosa que está dirigiendo el mundo socialista hacia el capitalismo". "Quizás es el comienzo del verdadero socialismo, el socialismo con rostro humano", le respondió el autor de Cien años de soledad. "No, créeme Gabo, esto va a ser un desastre" (Skierka 2004, 255). En realidad, las dudas de Fidel Castro antecedían largamente esta conversación citada. Ellas aparecen ya desde el año 1986, cuando la dirección del Partido Comunista de Cuba (PCC) optó por dar inicio al proceso conocido como "Rectificación", una respuesta evidente a los intentos reformadores desencadenados en la URSS. Ante la inminencia 
de un debilitamiento del comunismo mundial, Castro y los suyos reaccionaron para revelar, aunque sin criticar explícitamente a la URSS, sus diferencias con el camino trazado por el joven secretario general del PCUS. La "rectificación de errores y tendencias negativas" fue un proceso complejo destinado a interrumpir las reformas que se habían introducido desde 1976, autorizando, en restringidas oportunidades, las iniciativas económicas individuales. Fue también una manera de marcar una distancia con un líder soviético que gozaba de enorme popularidad en $\mathrm{Cuba}^{5}{ }^{5}$ en particular, en el seno de las juventudes del PCC (Kapcia 2009, 41), y de "re-cubanizar" la revolución, apartándose del espejo soviético que durante gran parte de los 70-80 se había erigido en modelo paradigmático. En efecto, en oposición al mercado regulado que se estaba imponiendo sin vuelta atrás en la URSS, los dirigentes cubanos buscaban reintroducir las nociones de austeridad igualitaria y de sacrificios morales encarnadas en la figura del Che Guevara, quien había teorizado estas cuestiones en la década de 1960. Empezaba así un acelerado proceso de distanciamiento con el socialismo mundial, acompañado de una evidente "autoctonización" del proceso cubano basada en la reivindicación de referencias revolucionarias locales.

Los debates concitados por la rectificación fueron relativamente abiertos, permitiendo a muchos observadores tomar conciencia de los posibles efectos de las nuevas tendencias soviéticas y fortaleciendo la confianza colectiva (fenómeno que se vio alimentado gracias a las recientes victorias obtenidas por el contingente militar cubano en África) mediante un retorno a las raíces de los primeros años revolucionarios. Pero si bien la rectificación fue sin lugar a dudas una respuesta a las crecientes influencias de la Perestroika, las diferencias entre Cuba y la URSS aún no eran evocadas explícitamente. Por otra parte, no hay indicios de que Fidel Castro mantuviera una mala relación con Gorbachov, quien, a pesar de su voluntad de reestructuración internacional, seguía prometiendo que la asistencia de su país no se interrumpiría. Además, las autoridades de la isla estaban perfectamente conscientes de los desastrosos efectos que una eventual retirada soviética de Cuba produciría

${ }^{5}$ Fidel Castro pudo comprobar por sí mismo la sorprendente popularidad de Mijaíl Gorbachov cuando este último aterrizó en el aeropuerto de La Habana en abril de 1989 y fue acompañado hasta su hotel por un cortejo de cerca de 500.000 cubanos expectantes. 
en la economía y, por extensión, en la legitimidad y supervivencia del gobierno revolucionario. Se trataba de un equilibro delicado, ya que La Habana debía hacer todo lo posible para no ahuyentar a los aliados del Este, mientras simultáneamente buscaba propulsar un proceso político llamado a evitar la crisis del "socialismo a la cubana".

Pero en la medida en que las reformas iban avanzando en la URSS, la prudencia inicial dejó de imponerse para dar paso a una crítica abierta de la "claudicación" soviética. Esta tendencia fue reforzada por las acusaciones, cada día más numerosas y despiadadas, que ciertos sectores de la opinión publica en la URSS reservaban al gobierno de los Castro. El paroxismo de este clima de tensión llegó cuando, en agosto 1989, el periódico Granma anunció el fin de la circulación de dos revistas provenientes de la URSS, Sputnik y Novedades de Moscú, ambas acusadas de propagar un estilo de vida burgués y occidentalizado (Rodríguez 2012, 51). A partir de ese momento, la escalada de recriminaciones mutuas resultó casi imposible de controlar. Los soviéticos tampoco parecían querer cuidar las apariencias, lo que quedó elocuentemente demostrado cuando, a comienzos de 1990, una delegación de políticos y periodistas se reunió con representantes de la diáspora cubana en Miami, entre ellos el muy activo opositor Jorge Más Canosa. Como se lo confiara Carlos Aldana, secretario del PCC, a Yuri Pavlov, la reunión no cayó nada bien en La Habana: "Vuestra participación en la conferencia de Miami les hace el juego a los enemigos de la Revolución Cubana" (Pavlov 1994, 161). En ese cuadro sensible, el "Líder Máximo" comenzó a evocar la idea de "dos tipos de socialismo", una forma de deslegitimar la experiencia soviética y de reprocharle su complacencia hacia el "imperialismo", que debía contrastarse con la "inflexibilidad" ideológica de las convicciones cubanas (Skierka 2004, 247). Fidel Castro empezaba ya a preparar a su gente para una batalla que se anunciaba dolorosa y a la cual tendrían que hacer frente sin la fidelidad acostumbrada del hermano mayor. Así lo dejaba entender cuando en el tradicional discurso del 26 de julio en 1989 hizo mención a la existencia de "dos tipos de comunistas", los que "pueden dejarse matar fácilmente, iy los comunistas que no nos dejamos matar fácilmente!” (Gaínza 1989). Ya nadie dudaba de que los cubanos estaban ahora llamados a librar un combate decisivo y que para ganarlo tendrían que recurrir, como veremos ahora, al fervor revolucionario de los "auténticos" ancestros del socialismo cubano. 


\section{EL REGRESO A LOS ORÍGENES REVOLUCIONARIOS: REEVALUACIÓN IDEOLÓGICA Y "SOCIALISMO AUTÓCTONO"}

Más allá de las querellas políticas, la crisis del socialismo mundial propulsó en Cuba un replanteamiento de la identidad revolucionaria y un profundo cuestionamiento de la excesiva identificación con el modelo soviético. El rol de la URSS como líder del comunismo mundial comenzó a erosionarse en la medida en que los caribeños constataron que Moscú buscaba un acercamiento con los Estados Unidos, en desmedro incluso de las alianzas tradicionales (Smith 1992, 152). Esta voluntad parecía confirmarse con el retiro progresivo de la asistencia soviética a las guerrillas centroamericanas —en particular a las de El Salvador y Guatemala-, así como al gobierno revolucionario de los sandinistas en Nicaragua (Pavlov 1994, 148-149). Todo ello no anunciaba nada promisorio para las autoridades de la isla, para quienes la ausencia de la URSS representaba una angustiante noticia. El intento de golpe de Estado en la URSS en agosto de 1991 acentuó el repudio interno hacia el autoritarismo, debilitando el extenuado "lobby pro cubano" que aún luchaba por sobrevivir en Moscú. La temida pero esperada decisión, anunciada por Gorbachov en septiembre de 1991, de negociar la salida de Cuba de las tropas soviéticas generó un gran impacto internacional, seguido de una fuerte indignación en La Habana y de la obvia exultación de Miami y Washington (Pavlov 1994, 230-232).

Un comentario de Fidel Castro publicado en el Granma ilustraba adecuadamente la ira de los dirigentes, a la vez que introducía una autocrítica reveladora de los pasos a seguir. Según Castro, la partida de los soviéticos era como "darles luz verde" a los enemigos del norte para que atacaran la isla. Recordaba luego la "primera traición" de Moscú, cuando Jrushchov optó por retirar sus misiles en 1962 sin consultar previamente a las autoridades del territorio en el que estaban implantados (Pavlov 1994, 233-234). Esta referencia al pasado es elocuente. A partir de ahora, habiendo comprobado la inconsistencia de la URSS por partida doble, Cuba tendría que retrotraerse a los primeros años, cuando la revolución aún hundía sus raíces en su propia historia y antes de que una alianza definitiva hubiese sido entablada con la potencia del Este. La Revolución Cubana no sólo tendría que aprender a vivir sin ayuda exterior, sino que también tendría que despojarse de las vestiduras ideo- 
lógicas "universalistas" y emprender un camino propio hacia el verdadero socialismo.

Las críticas hacia los excesos de identificación con el modelo del Este arreciaron en la esfera pública, estimuladas por el propio Fidel Castro, quien evocaba, por ejemplo, "nuestro error de deificación de la URSS" (Pavlov 1994, 246). Teniendo así el visto bueno del Comandante, el medio intelectual comenzó a interrogarse sobre las bases adecuadas sobre las cuales la situación presente debía erigirse. Una obra colectiva aparecida en 1994, El derrumbe del modelo eurosoviético, constituye un adecuado reflejo de este espíritu. En ella, el doctor Ramón Sánchez Noda aclara desde el principio que ante el escenario actual es indispensable "reasumir trincheras verdaderamente revolucionarias" y "desembarazarnos de las posiciones dogmáticas", a saber, el marxismo ortodoxo preconizado por la extinta Unión Soviética. En clara ruptura con la historia postrevolucionaria de la URSS, el autor se alegra al constatar que, al reivindicar el pensamiento de Marx, de Lenin, pero también de Fidel y del Che, "reapareció el hilo conductor que nos permitió escapar de ese laberinto" (Sánchez Noda 1994, 3). Mediante estas palabras introductorias, el pensador cubano pretende posicionar a los revolucionarios locales (Guevara, Fidel Castro, entre otros) en el mismo nivel que los "clásicos", insistiendo sobre la necesidad de desarrollar un proceso renovado cimentado "en sus raíces históricas, y por decisión inalterable de nuestro pueblo" (Sánchez Noda 1994, 5).

La alusión al guerrillero Ernesto Guevara no es casual. Constituye, en realidad, uno de los aspectos más notables del replanteamiento ideológico de esta nueva fase revolucionaria, marcada por las agravadas consecuencias de lo que se conoce como "Periodo Especial en Tiempos de Crisis". Desde el año 1960, cuando el Che redactó su famosa obra, La guerra de guerrillas, el argentino se había erigido en el principal adversario de la adopción de un cuerpo doctrinario inspirado en los influjos de los nuevos aliados soviéticos. Su teoría del "foquismo", de hecho, se oponía drásticamente a las prioridades de las administraciones soviéticas en tiempos de Jrushchov y Leonid Brezhnev, así como negaba un elemento básico del pensamiento marxista oficial: la preponderancia del Partido Comunista para la formación de una auténtica conciencia revolucionaria. Para el Che Guevara no era necesario que las masas hubiesen sido adoctrinadas para desencadenar el proceso in- 
surreccional, ya que el "foco", es decir, el núcleo campesino liderado por una vanguardia armada, podía imponer las condiciones para una profunda transformación social (Guevara 2010,33). Pero más allá de estas herejías doctrinarias, el Che tampoco evitaba criticar, a veces en durísimos términos, la pasividad de los soviéticos, como cuando en su célebre discurso de Argel en 1965 cuestionó duramente a los países socialistas, "cómplices de la explotación imperialista", por su política hacia el Tercer Mundo (Reid-Henry 2009, 304). No debiera extrañarnos, por ende, que la literatura guevarista haya tendido a desaparecer de los estantes en los años 70 y comienzos de los 80 (Kapcia 2009, 108), cuando la cooperación con el Kremlin alcanzó su apogeo.

Algo similar ocurrió incluso con el "apóstol de la patria", José Martí (1853-1895), cuya figura - tan ensalzada tanto por la oficialidad cubana como por los exiliados de Miami - fue relegada a la de una suerte de precursor histórico de los avances actuales (Kapcia 2000, 178), dejando así de personalizar, como en un primer momento, el cuerpo filosófico constitutivo del proceso revolucionario. El paradigma soviético, que desplazaba el pensamiento autóctono, se había impuesto irremisiblemente. Pero a comienzos de los 90, cuando, como hemos observado, se hacía urgente recuperar el fervor de un pasado autónomo, tanto el Che como Martí fueron reactualizados a manera de manifestación de "cubanidad" (Miller 2003, 150) y puestos nuevamente en el tapete para servir de pruebas fehacientes del carácter independiente de la Revolución Cubana.

Más que un esfuerzo simbólico, esta reivindicación adquirió también una dimensión institucional que merece ser destacada. La Constitución de 1976, largamente ajustada en función del modelo soviético, definía al PCC como una organización "marxista-leninista"; sin embargo, un cambio fue introducido en 1992, cuando en este mismo artículo 5 se antepuso a la definición anterior un adjetivo significativo: "martiano y marxista-leninista" (Pavlov 2012, 232). También quedaba inscrito en la carta magna que "el ideario de José Martí y las ideas socio-políticas de Marx, Engels y Lenin" constituían la fuerza impulsora de la revolución. Resulta sumamente revelador del momento crucial que estaba atravesando el proyecto ideológico cubano que el nombre de Martí, un intelectual y luchador que no se inscribe en la tradición marxista, precediera al de los "clásicos" del socialismo, desplegando un fuerte com- 
ponente nacionalista. Ya nadie podía dudar de que ahora la prioridad debía ser otorgada a "lo autóctono" (Zanetti 2009, 92), mientras que la filiación universal, sin ser negada, pasaba a un segundo plano.

Vale la pena señalar que la permanencia de Cuba como uno de los pocos bastiones del socialismo en el mundo, ante la expansión de las fuerzas hostiles (incluido en la antigua aliada Nicaragua que abandonó, mediante elecciones, el proyecto revolucionario sandinista en 1990), creó un sentido de responsabilidad casi mesiánico. Con el derrumbe de la esfera del Este, el papel de la isla adquiría una dimensión insospechada, de resonancias globales. Pocos expresaron mejor que el profesor Arnaldo Silva León la nueva misión de los comunistas cubanos, de quienes dependía, "tal vez decisivamente, el futuro del socialismo para la humanidad de ese Tercer Mundo". Por ello, insiste Silva León, lo que vive Cuba "es más que una lucha meramente nacional, es internacional"; y prometía casi con un grito de guerra: "No les fallaremos" (Silva León 1994, 138).

Por otro lado, bajo estas nuevas premisas la manera de estudiar el marxismo también debía repensarse, ya que la "caída del coloso" evidenciaba que la "lógica universal sólo puede existir a través de las lógicas particulares y singulares de los procesos históricos concretos". De ahí que la propia teoría política necesitara "renovarse de manera específica en cada contexto" y sin ser diseñada "en abstracto". La lección parece haber sido particularmente bien asumida por el filósofo, ex becario de la Universidad Estatal de Moscú, José Ramón Fabelo Corzo, quien concluía en un artículo de 1994: "Es hora de dar fin al modelo único y a-histórico del socialismo" (Fabelo Corzo 1994, 17). Lo interesante aquí es que mediante este tipo de reflexiones, los pensadores de los noventa volvían a evocar los debates de la segunda mitad de los años sesenta, cuando aún había un amplio margen para proponer una visión "heterodoxa" del marxismo, basada en las ideas de pensadores críticos de izquierda, como Louis Althusser, Georg Lukács y, por supuesto, el propio Che Guevara. Las constataciones de Fabelo Corzo, por ejemplo, hacían eco de la estridente "polémica de los manuales" de 1966, durante la cual se puso en tela de juicio las doctrinas totalizadoras del pensamiento soviético contemporáneo y de sus defensores en Cuba.

Aquella controversia, desarrollada en la revista Teoría y Práctica, enfrentó a dos corrientes en torno a la pertinencia de importar manuales 
soviéticos para la enseñanza teórica en las Escuelas de Instrucción Revolucionarias (EIR) de la isla: los llamados "dogmáticos", defensores de un camino basado en el modelo de la URSS, y una joven generación de pensadores pertenecientes a la Universidad de La Habana. Uno de ellos, Aurelio Alonso, reaccionó contra la idea, evocada en un número anterior de la revista, de que era necesario extraer "lo universal contenido en los manuales" soviéticos (Pérez y De la Uz 1966, 14-15). El joven filósofo criticó también las construcciones "reproducidas religiosamente" y el uso del marxismo concebido como "juguete teórico". En definitiva, para Alonso y sus compañeros era preferible privilegiar una estructura de pensamiento crítica fundada en una "rigurosa valoración histórica", "que crea, que critica, que transforma"; es decir, que se moldea en función de los anclajes locales y de las particularidades de la historia y de las tradiciones de cada realidad (Alonso 1966, 13-14). El grupo de Alonso, que durante la segunda mitad de los años 60 gozó de gran visibilidad gracias a la publicación de la revista Pensamiento Crítico y fue decididamente respaldado por Fidel Castro, ${ }^{6}$ terminó, sin embargo, siendo parcialmente acallado cuando se inició el famoso Quinquenio Gris. ${ }^{7}$

No cabe duda de que esta visión crítica hacia lo soviético no experimentó el mismo rechazo a inicios de los 90, cuando era exactamente este distanciamiento con respecto a la URSS postrevolucionaria lo que se buscaba incentivar. Cómo no pensar en los principales representantes de la generación de Pensamiento Crítico cuando leemos el ensayo de Rubén Zardoya, para quien el marxismo que estaba en crisis era el que "hurga en las obras de los clásicos como en un cofre de piratas, en busca de definiciones (...) sin preocuparse apenas de que satisfagan las más elementales exigencias de la propia lógica que se absolutiza" (Zardoya 1994, 23). En este nuevo contexto, los filósofos "críticos" como Fernando Martínez Heredia y el propio Alonso volvieron lógicamente a imponerse en el debate intelectual, sin abandonar, por cierto, sus apren-

${ }^{6}$ Fidel Castro criticó en más de una oportunidad lo que se conocía como "manualismo", en referencia a la confianza excesiva otorgada a los textos importados de la URSS.

${ }^{7}$ En agosto de 1971, se optó por suspender la circulación de la revista Pensamiento Crítico, dando inicio a un periodo en el que, según las palabras de Fernando Martínez Heredia, "las necesidades del Estado parecían más decisivas que los criterios ideológicos" (Fornet 2013, 256). 
siones en torno al modelo de la extinta URSS. ${ }^{8}$ No es casualidad que hasta hace pocos años, Aurelio Alonso, hoy anciano y aureolado de un gran prestigio, seguía insistiendo en la necesidad de "reinventar el socialismo" cubano y de cuestionar "de modo integral" el "viejo modelo" (Alonso 2007).

La ruptura con el pasado soviético afectó prácticamente todos los aspectos de la vida política y cotidiana de la isla, desde la presencia cultural a los intercambios humanos, generando, para algunos, un trauma identitario de difícil resolución. El idioma ruso, el que, como vimos, se enseñaba incluso mediante cursos difundidos por la radio — gracias a los cientos de miles de cubanos que tuvieron la posibilidad de formarse en la URSS-, desapareció. Ya en 1989 se dieron instrucciones de interrumpir las clases de ruso en los colegios para que fueran remplazadas por el inglés. Lo mismo sucedió en las universidades, donde algunos profesores, como Xiomara García, debieron iniciar a avanzada edad formaciones de inglés para "ponerse al día" después de toda una vida transmitiendo el idioma de Dostoievski (García 2015). Fidel Castro ofrecería en el Granma una elocuente explicación a este giro, apuntando al atraso soviético, donde hay que "esperar diez a quince años" antes de que se traduzcan los buenos trabajos (Pavlov 1994, 247).

Como una serie de buenos estudios literarios y cinematográficos lo han demostrado recientemente, el impacto cultural que produjo el desmoronamiento de la amistad cubano-soviética dejó a pocos indiferentes. La abrupta interrupción de los intercambios y de la importación de innumerables productos provenientes del mundo del Este (electrodomésticos, libros, vehículos, comida enlatada, revistas de buen diseño y un largo etcétera) engendró un sentimiento de "nostalgia", aún perceptible, marcado por el recuerdo de una era de "abundancia" que hoy parece simplemente obsoleta. Como lo subraya Damaris Puñales-Alpízar, una de las más asiduas estudiosas de las huellas dejadas por la URSS en suelo cubano, la escasez relativa de contactos con otras realidades nacionales y la cotidiana presencia —estética, gastronómica, técnica,

${ }^{8}$ Una anécdota ilustra correctamente el estado de espíritu de Fernando Martínez Heredia respecto a la URSS. Cuando hace un par de años lo contactamos para intentar obtener una entrevista que nos permitiera hablar de la Unión Soviética, el respetado intelectual cubano se negó, arguyendo que "no tengo vivencias personales" pertinentes para abordar este tema. 
humana- de la URSS engendró en amplias capas de la sociedad un afecto hacia los referentes venidos del Este, configurando una perdurable "comunidad sentimental soviético-cubana" (Puñales-Alpízar 2012, 19-24). Esto se ha traducido, para muchos, en una dolorosa fractura emocional, muy visible en nuestros días en las abundantes producciones culturales que intentan penetrar en los efectos de la violenta desaparición del "hermano soviético" (Pedemonte 2017, 136-141). ${ }^{9}$

Más allá de sus esperadas repercusiones en Cuba, los efectos desmoralizadores de la caída del socialismo mundial también se dejaron sentir en el resto de las naciones latinoamericanas, donde, para muchos militantes fieles a la URSS, el colapso condujo a una pérdida irreversible de un paradigma (Castañeda 1993, 244). Es tiempo de interrogarnos, mediante el ejemplo de Chile, sobre la dimensión continental de la pérdida del "horizonte" soviético y sobre la re-estructuración de la izquierda ante la desaparición de un referente - a veces endiosado, otras veces duramente acusado-, en torno al cual muchas organizaciones comunistas definieron su ADN ideológico.

\section{LA IZQUIERDA EN AMÉRICA LATINA Y EL DOBLE ENTIERRO DEL MODELO SOVIÉTICO}

El Partido Comunista de Chile (PCCh) fue por muchos años uno de los más estrictos adeptos de la Unión Soviética (Friedman 2015, 156). En ella sus militantes hallaron un faro ideológico que iluminaba el tortuoso camino por el cual transcurrió en el medio político local. La abrumadora mayoría de las decisiones internacionales adoptadas por el "hermano mayor" fueron respaldadas con ahínco por los comunistas locales, incluidas las intervenciones en Hungría (1956) y Checoslovaquia (1968). Así, mientras tensiones crecientes dividían el marxismo internacional, el PCCh optó con sincera convicción respaldar a sus aliados del Este. Como lo recuerda el militante Alejandro Toro Herrera, ya en 1959, cuando incipientes signos de la ruptura sino-soviética se veían brotar, su organización no vaciló en posicionarse detrás de la URSS. El propio Toro Herrera redactaría más tarde un artículo para condenar las "calumnias" de los maoístas y llamar la atención sobre el carácter "revi-

\footnotetext{
${ }^{9}$ Recomendamos el revelador documental de Enrique Colina, Los bolos en Cuba y una eterna amistad (2011).
} 
sionista" y "egoísta" del gigante asiático (Toro Herrera 2014, 25-26). ${ }^{10}$ De la misma manera, en la medida en que las divergencias entre la Cuba castrista y la URSS se hacían visibles, sobre todo hacia mediados de los años sesenta, el PCCh tampoco dudó en subrayar su adecuación a la doctrina de la "coexistencia pacífica" frente al radicalismo cubano, que tendía a acentuar su respaldo a la "vía insurreccional" defendida por ciertos movimientos latinoamericanos. En respuesta a su irrestricta fidelidad, los comunistas chilenos recibieron una importante asistencia de Moscú que, desde 1955, se expresó en aportes financieros, pero que también incluyó una serie de beneficios no monetarios, como viajes de formación, becas de estudio, envío de material cultural destinado a los Institutos Chileno-Soviéticos de Cultura, etcétera (Ulianova y Fediakova 1998, 141-142).

Después del golpe de Estado de 1973, muchos comunistas encontrarían refugio en la URSS, donde gozaron de una situación privilegiada, permitiéndoles llevar a cabo una amplia campaña de solidaridad y de denuncia contra las atrocidades que se estaban cometiendo en Chile. Si bien la postura del PCCh — cuya dirección exterior se había instalado en Moscú- se hacía cada vez más beligerante, para incorporar finalmente la resistencia armada como una forma adecuada de lucha contra la dictadura, su fidelidad no estuvo en tela de juicio, alineándose con el Kremlin en su lucha contra el eurocomunismo (Riquelme 2009, 119). Pero lo interesante aquí es que, incluso para un partido que había hecho de la URSS una inspiración incontestada, la desintegración de esta última provocó un dramático impacto que se acompañaría, como en el caso cubano, de cierto replanteamiento ideológico. Se planteó incluso la posibilidad, a mediados de 1991, de excluir el término "marxismo-leninismo" de los principios partidarios, y, si bien esto no aconteció, observamos un esfuerzo evidente de parte del PCCh por recuperar sus raíces nacionales. El secretario general Volodia Teitelboim, por ejemplo, se esforzó por desprenderse de la tradicional obsecuencia hacia la historia soviética para rescatar el pasado local de su partido: al insistir sobre el hecho de que el "PC no es una creación exógena", sino que "nació antes

${ }^{10}$ Debemos recordar, sin embargo, que un grupo menor de militantes comunistas optaría por seguir la vía maoísta y fundar una nueva organización, Espartaco, que más tarde daría origen al Partido Comunista Revolucionario (Johnson 1970, 247-257). 
de la Revolución Rusa" (Riquelme 2009, 260), Teitelboim pretendía encauzar su organización en un nuevo camino ideológico legitimado por una narrativa anclada en las luchas nacionales y, por ende, emancipada de la precedente identidad militante, por tan largo tiempo indisociable de las preconizaciones soviéticas. Tal como en Cuba, donde después de la caída de la URSS Martí y el Che volvieron a erigirse en los auténticos guías de la revolución, este trance amargo implicó igualmente la reivindicación sistemática del verdadero fundador del comunismo chileno: Luis Emilio Recabarren. El nuevo programa del PCCh, publicado en noviembre de 1991, a pocas semanas de la declaración definitiva de disolución de la URSS, distinguía su propia historia de la del triunfo bolchevique, destacando así el nacimiento del Partido Obrero Socialista (1912) como el genuino hito fundador de la tradición comunista criolla: "Este, y no otro es nuestro origen" (Riquelme 2009, 270).

En términos electorales, el colapso soviético deslegitimó el proyecto político del PCCh a los ojos de muchos ciudadanos que no lograrían disociarlo del modelo que acababa de derrumbarse. El paso a la oposición durante el primer gobierno democrático postdictadura militar, dirigido por el democratacristiano Patricio Aylwin (1990-1994), en 1991, marginalizó definitivamente al partido del poder, conllevando a un magro resultado en las presidenciales de 1993, cuando su candidato, Eugenio Pizarro, obtendría tan sólo el 4,7 por ciento de los votos, incluso superado por dos outsiders, José Piñera y Manfred Max Neef. Entraba así el comunismo chileno en una era de aislamiento político que recordaba los años anteriores al Frente Popular (Riquelme 2009, 288). Esta debacle no sería revertida en 1999, cuando Gladys Marín, a pesar de las expectativas, apenas superaría el 3 por ciento de los votos en las elecciones presidenciales.

A diferencia de los antiguos aliados comunistas de los días de la UP, los actores que, desde la izquierda, cimentaron el camino democrático bajo las banderas de la Concertación de Partidos por la Democracia provenían de las corrientes críticas del marxismo, aprehensivas de la política exterior soviética. En efecto, los militantes socialistas que asumieron responsabilidades ejecutivas a partir de 1990, tal como los antiguos representantes del MAPU, se caracterizaron en los años sesenta por adoptar una visión reticente al modelo propuesto por la URSS. Una figura como Ricardo Núñez, por ejemplo, quien se convirtió en 
presidente del Partido Socialista unificado, antes había sido el líder del ala "renovada" del partido, más alejada de la URSS que la corriente de Clodomiro Almeyda. En los años sesenta y setenta, Núñez y otros no ocultaron sus inquietudes hacia la superpotencia del Este, mientras indagaban en las lecturas de autores desechados por la oficialidad soviética (Núñez 2013, 55, 80). En términos generales, el Partido Socialista Chileno (PSCh) nunca había manifestado una estricta disciplina pro URSS, prefiriendo presentarse como una alternativa entre los proyectos encarnados por los dos "gigantes" (Cancino 2013, 117-120) y cuyo horizonte en los sesenta y setenta parecía perfilarse cada vez más como reflejo de la Revolución Cubana.

Se ha hablado mucho también del papel crucial jugado por la "generación MAPU" en los primeros años de administración concertacionista. Personajes como Enrique Correa, Eugenio Tironi, Jaime Gazmuri, José Miguel Insulza, José Joaquín Brunner u Óscar Guillermo Garretón contribuyeron decididamente a forjar el destino democrático por el que Chile transitaría tras los 17 años de Augusto Pinochet en el poder. Provenientes de una tradición cristiana (el MAPU se escindió en 1969 del Partido Demócrata Cristiano), para los jóvenes MAPU de los sesenta - al igual que para sus colegas socialistas- la URSS nunca constituyó un modelo a imitar. En vez de familiarizarse con los manuales soviéticos ortodoxos, estos militantes preferían adentrarse en los escritos de pensadores alternativos del marxismo, como Louis Althusser, cuyas obras controvertidas fueron traducidas en Chile por una de sus discípulas (también ex integrante del PDC), Marta Harnecker. Como queda establecido en su programa de finales de 1972, desde el punto de vista del sistema mundial, el MAPU había optado por no tomar partido en la feroz contienda China-URSS, mientras que simultáneamente negaba la pertinencia de la "coexistencia pacífica" como "principio estratégico internacional" (Valier 1974, 8).

Vemos así que, con la marginalización del PCCh a comienzos de los noventa, la tradición de izquierda de quienes estaban asumiendo las riendas del poder en el Chile postdictadura era crítica del marxismo y reticente a aceptar el rol conductor de la URSS. El drama de la "caída de las catedrales" (Guastavino 1990) tuvo entonces un cariz doble: mientras el bloque del Este se desmembraba, pocos en la cúpula de la jerarquía administrativa de Chile observaban este inapelable desenlace con nostalgia. 
En América Latina, globalmente, para la izquierda menos proclive a la renovación liberal, la desaparición de la URSS como paradigma revolucionario real favoreció la atracción creciente que ejercía el ejemplo de Cuba, una isla que, a pesar de los severos embates, logró preservar el legado del socialismo. Los comunistas chilenos, que habían atravesado en la década de 1960 una etapa de profundas divergencias estratégicas con el modelo castrista, fortalecieron su compromiso con La Habana ante la evidencia de la inesperada supervivencia de la administración de Fidel Castro. A pocos días del triunfo del No a Pinochet en el plebiscito de 1988, un documento oficial del PCCh analizaba la adopción de una "vía pacífica" hacia el socialismo, doctrina defendida con convicción por el partido en los años 60 y durante el gobierno de la UP, evocando críticamente las "ilusiones legalistas" estimuladas por "los hábitos de la democracia burguesa". Lo que podría haber evitado este error estratégico, continúa el texto, es haber asimilado de mejor manera las enseñanzas de la Revolución Cubana: "No nos apropiamos a fondo y desde el comienzo de sus grandes lecciones" (Riquelme 2009, 166).

Superada la fase más aguda de la crisis de la izquierda a comienzos de los años noventa (Webber 2017, 10-13), Cuba ha logrado seguir inspirando a los revolucionarios latinoamericanos. Desde 1999, cuando el venezolano Hugo Chávez accedió por primera vez a la presidencia, una ola de gobiernos reformistas ha sacudido el territorio del subcontinente (Néstor Kirchner en Argentina, Lula da Silva en Brasil, Evo Morales en Bolivia, Rafael Correa en Ecuador, José Mujica en Uruguay, Daniel Ortega en Nicaragua, Mauricio Funes en El Salvador, a los que habría que sumar una serie de pequeños Estados caribeños), todos articulados, en parte, gracias a la personalidad y liderazgo regional del nuevo Mandatario. Para Chávez, un militar cristiano con una visión ideológica difícil de definir, Cuba representaba un ejemplo inspirador que contribuyó a guiar los primeros pasos del gobierno revolucionario. Aunque sin ocultar sus diferencias con el castrismo, y respetando el calendario electoral, no cabe duda de que la presencia de la Cuba socialista y la experiencia de Fidel Castro ayudaron a perfilar el camino del chavismo. Hugo Chávez estuvo por primera vez en La Habana en 1994, poco después de ser liberado tras su tentativa frustrada de golpe de Estado en 1992, fue acogido por el "Líder Máximo" en el aeropuerto y efectuó un polémico discurso en el que se refirió a Cuba como un "bastión de la dignidad 
latinoamericana" (Jones 2008, 192-193). Los lazos se intensificaron después de la asunción del mando de Chávez, quien optó por establecer una serie de acuerdos generosos, fortalecidos con la creación del ALBA (Sánchez 2007, 22-33), una organización internacional que dio cuerpo a las tendencias de izquierda en el subcontinente.

Pero mientras Chávez multiplicaba sus elogios hacia Cuba e incluso hacia el líder histórico de la China socialista, Mao (Gott 2011, 189), no encontramos similares expresiones respecto al modelo soviético. Las grandes figuras de la URSS no parecen ocupar el ideario chavista; es más, cuando se trata de asimilar el marxismo, el comandante prefirió adentrarse en los escritos del Che Guevara, de Gramsci o del propio Mao (Harnecker 2002, 9, 100). Pero el suyo es sobre todo un proyecto ideológico (calificado de "socialista" sólo a partir de 2005) enraizado en las condiciones y referencias locales, con constantes alusiones al "árbol de tres raíces" (Harnecker 2002, 14): Simón Bolívar, Simón Rodríguez y Ezequiel Zamora (Gott 2011, 91-116). En un guiño a sus aliados cubanos, José Martí también se ha ubicado en un sitial privilegiado del panteón heroico del chavismo. En cuanto a la URSS, cuando el líder venezolano se refería a esta experiencia, lo hacía más bien para acentuar sus discrepancias y ver en los errores del modelo soviético una enseñanza provechosa para la construcción de su particular vía revolucionaria. En enero de 2007, en Río de Janeiro, Chávez se esforzó por definir lo que había bautizado como "socialismo del siglo XXI", un esquema explícitamente diferente al sistema de la URSS, un experimento "fracasado", ya que "no era democrático y no daba poder al pueblo". Chávez concluía este discurso con una declaración reveladora de su ambición programática: "Tenemos que construir un modelo socialista que no copie modelos de otros países" (Harris 2009, 39).

De la misma manera, los principales estandartes de la "nueva izquierda" en América Latina han adoptado también un modelo profundamente enraizado en las peculiaridades de cada nación, abandonando la pretensión, recurrente durante la Guerra Fría (Westad 2007), de adaptar en el escenario local un sistema alógeno. Rafael Correa (2007-2017) parece estar más influido por un pensamiento social cristiano, muy presente en la Universidad Católica de Lovaina (Bélgica), donde realizó su doctorado; la Bolivia de Evo Morales hunde sus raíces ideológicas en el 
katarismo y diversas reivindicaciones indigenistas; ${ }^{11}$ Sánchez Ceren en El Salvador y Daniel Ortega en Nicaragua han asumido el poder con un programa que poco tiene que ver con los móviles de las luchas revolucionarias que lideraron en tiempos de la Guerra Fría. En todos ellos, la referencia soviética se halla ausente, revelando adecuadamente una de las características más sobresalientes de la izquierda del continente: la emancipación definitiva respecto a los paradigmas globales para la elaboración de sus propios proyectos "revolucionarios".

La abrupta caída de la Unión Soviética generó sin duda una situación dramática para las esperanzas del socialismo latinoamericano, que tuvo que replantear sus posicionamientos en función del nuevo cuadro global, mientras que propulsó una voluntad decidida a pensar la doctrina política en consonancia con los rasgos del país. Vimos cómo los intelectuales cubanos, impulsados por la crítica amarga y despiadadamente abierta de Fidel Castro, elaboraron nuevas definiciones ideológicas, desafiantes hacia la anacrónica valoración del sistema de la URSS. Este proceso fue acompañado de una reivindicación sistemática (y podríamos decir que crucial para la supervivencia del socialismo cubano) de las figuras que encarnan la autenticidad de la revolución, en particular José Martí y Ernesto Guevara. Una tendencia similar puede ser identificada en el caso de los partidos que tradicionalmente manifestaban mayor fidelidad hacia el ejemplo de la URSS, como el PCCh.

En los dos decenios pasados, cuando una ola de gobiernos autocalificados de "revolucionarios" se implantaron en numerosos países del continente latinoamericano, constatamos que las alusiones hacia la experiencia soviética han sido prácticamente inexistentes y que, cuando ella se mencionaba, fue más bien para subrayar las insuficiencias de un modelo derrumbado y así legitimar un proyecto autónomo de izquierda, liberado de la "tutela" que muchos partidos marxistas asumían sin pudor en los decenios de la Guerra Fría. Así, en un periodo sorprendentemente breve, la URSS no sólo ha desaparecido del escenario mundial; nos encontramos también ante la configuración de una doble derrota

11 Álvaro García Linera, el perenne vicepresidente de Evo Morales, considerado como el "teórico" del gobierno, posee un pensamiento político ecléctico e indefinible bajo los cánones conocidos. Pero cuando se trata de aludir a los "clásicos", García Linera prefiere, al igual que Hugo Chávez, acudir a Mao o al italiano Antonio Gramsci, sin mencionar el pensamiento soviético postrevolucionario (Webber 2017, 162-163). 
de un modelo que alimentó por casi un siglo las aspiraciones de tantos revolucionarios a lo largo y ancho de la Tierra: por un lado, el fracaso definitivo de la experiencia política y, por otro, la extinción de su poderoso arrastre ideológico.

\section{REFERENCIAS}

Alonso, Aurelio. 1966. "Manual... o no manual: diálogo necesario". Teoría y Práctica 30: 12-18.

. 2007. "Hay que 'reinventar' el socialismo en Cuba". La Jornada, 17 de diciembre. http://www.jornada.unam.mx/2007/12/17/index.php?section=mun do\&article $=027 \mathrm{e} 1 \mathrm{mun}$

Brutents, Karel. 1992. "A New Soviet Perspective". En The Russians Aren't Coming: New Soviet Policy in Latin America, editado por Wayne Smith. Boulder: Rienner.

Cancino Troncoso, Hugo. 2013. "El Partido Socialista de Chile, 1945-1970". En La Guerra Fría y las Américas, editado por Avital Bloch \& María del Rosario Rodríguez. Morelia: Universidad Michoacana de San Nicolás de Hidalgo.

Castañeda, Jorge. 1993. Utopia Unarmed: The Latin America Left after the Cold War. New York: Knopf.

Castro, Fidel. 1989. "Discurso pronunciado por Fidel Castro Ruz, Presidente de la República de Cuba, en la sesión extraordinaria y solemne de la Asamblea Nacional, con motivo de la visita a nuestro país del compañero Mijaíl S. Gorbachov". http://www.cuba.cu/gobierno/discursos/1989/esp/f040489e.html

Cino Colina, Ileana. 2010. "Enseñando ruso". Revolución y Cultura 1: 24-27.

Fabelo Corzo, José Ramón. 1994. "El marxismo en los umbrales del siglo XXI". En El derrumbe del modelo eurosoviético. La Habana: Editorial Félix Varela.

Fernández, Pablo Armando. 2012. La mano del tiempo. La Habana: Letras Cubanas.

Fornet, Ambrosio. 2007. "El Quinquenio Gris: Revisitando el término". Criterios: $1-22$.

Fornet, Jorge. 2013. El 71: Anatomía de una crisis. La Habana: Letras Cubanas.

Friedman, Jeremy. 2015. Shadow Cold War: The Sino-Soviet Competition for the Third World. Chapel Hill: University of North Carolina Press.

Gaínza, Carlos. 1989. "Castro asegura que la Revolución Cubana proseguirá aunque la URSS se desintegre". El País, 28 de julio. https://elpais.com/ diario/1989/07/28/internacional/617580009_850215.html

García, Xiomara. 2015. Entrevista con el autor. La Habana, 9 de julio del 2015.

Gleijeses. Piero. 2002. Conflicting Missions: Havana, Washington and Africa, 1959-1976. Chapel Hill: University of North Carolina Press.

Gott, Richard. 2011. Hugo Chávez and the Bolivarian Revolution. Londres: Verso. 
Guastavino, Luis. 1990. Caen las catedrales. Santiago: Hachette.

Guevara, Che. 2010. La guerre de guérilla. París: Flammarion.

Harnecker, Marta. 2002. Hugo Chávez Frías: un hombre, un pueblo. San Sebastián: Tercera Prensa.

Harris, Richard. 2009. "Cuban Internationalism, Che Guevara and the Survival of Cuba's Socialist Regime". Latin American Perspectives 36 (3): 27-42.

Johnson, Cecil. 1970. Communist China \& Latin America, 1959-1967. New York: Columbia University Press.

Jones, Bart. 2008. The Hugo Chávez Story: From Mud Hut to Perpetual Revolution. Londres: Bodley Head.

Kapcia, Antoni. 2000. Cuba: Island of Dreams. Oxford: Berg. 2009. Cuba in Revolution: A History since the Fifties. Londres: Reaktion Books.

Kaufman, Edy. 1976. The Superpowers and their Spheres of Influence. The United States and the Soviet Union in Eastern Europe and Latin America. London: Croom Helm.

Khrouchtchev, Nikita. 1971. Souvenirs. París: Robert Laffont.

Latrèche, Leila. 2011. Cuba et l'URSS. 30 ans d'une relation improbable. París: L'Harmattan.

Mikoyan, Sergo. 1992. "The Future of the Soviet-Cuban Relationship". En The Russians Aren't Coming: New Soviet Policy in Latin America, editado por Wayne Smith Boulder: Rienner.

Miller, Nicola. 2003. "The Absolution of History: Uses of the Past in Castro's Cuba". Journal of Contemporary History 38: 147-162.

Núñez, Ricardo. 2013. Trayectoria de un socialista de nuestros tiempos. Santiago: Ediciones Universidad Finis Terrae.

Paszyn, Danuta. 2000. The Soviet Attitude to Political and Social Change in Central America, 1979-1990. Case-Studies on Nicaragua, El Salvador and Guatemala. Londres: MacMillan Press.

Pavlov, Yuri. 1994. Soviet-Cuban Alliance: 1959-1991. Miami: University of Miami.

- 2012. "Socialism as the main Soviet Legacy in Cuba". En Caviar with Rum: Cuban-USSR and the Post-Soviet Experience, editado por Jacqueline Loss \& José Manuel Prieto. New York: Palgrave Macmillan.

Pedemonte, Rafael. 2017. "Birches too difficult to cut down: The rejection and assimilation of the Soviet reference in Cuban culture". International Journal of Cuban Studies 9: 127-141.

Pérez, Humberto \& Félix de la Uz. 1966. “¿Contra el manualismo?, ¿contra los manuales? o ¿contra la enseñanza del marxismo-leninismo?”. Teoría y Práctica 28: 10-17.

Politzer, Patricia. 1990. Altamirano. Santiago: Melquíades. 
Puñales-Alpízar, Damaris. 2012. Escrito en cirílico: el ideal soviético en la cultura cubana posnoventa. Santiago: Cuarto Propio.

Reid-Henry, Simon. 2009. Fidel and Che: A Revolutionary Frienship. Londres: Sceptre.

Riquelme, Alfredo. 2009. Rojo atardecer: el comunismo chileno entre dictadura y democracia. Santiago: Dirección de Bibliotecas, Archivos y Museos, Centro de Investigaciones Diego Barros Arana.

Rodríguez, Reina María. 2012. "Nostalgia". En Caviar with Rum: Cuban-USSR and the Post-Soviet Experience, editado por Jacqueline Loss \& José Manuel Prieto. New York: Palgrave Macmillan.

Sánchez, Germán, 2007. Cuba and Venezuela: An Insight into Two Revolutions. Melbourne: Ocean Press.

Sánchez Noda, Ramón. 1994. "Introducción”. En El derrumbe del modelo eurosoviético. La Habana: Editorial Félix Varela

Silva León, Arnaldo. 1994. "Socialismo: Sistema y modelos. La experiencia cubana". En El derrumbe del modelo eurosoviético. La Habana: Editorial Félix Varela.

Skierka, Volker. 2004. Fidel Castro: A Biography. Cambridge: Polity Press.

Smith, Wayne. 1992. "Comments on the Soviet and Cuban Perspectives". En The Russians Aren't Coming: New Soviet Policy in Latin America, editado por Wayne Smith Boulder: Rienner.

Taubman, William. 2003. Khrushchev: the Man and his Era. New York: Norton \& Company.

Toro Herrera, Alejandro. 2014. Memorias de un comunista discrepante. Contra el stalinismo y la aventura. Santiago: LOM.

Ulianova, Olga \& Eugenia Fediakova. 1998. "Algunos aspectos de la ayuda financiera del Partido Comunista de la URSS al comunismo chileno durante la Guerra Fría”. Estudios Públicos 72: 113-148.

Vacs, Aldo César. 1984. Discreet Partners: Argentina and the USSR since 1917. Pittsburgh: University of Pittsburgh Press.

Valier, Anne. 1974. MAPU 1970-1973: recueil de textes. París: Politique Hebdo.

Webber, Jeffery. 2017. The Last Day of Oppression, and the First Day of the Same: The Politics and Economics of the New Latin American Left. Chicago: Haymarket Books.

Westad, Odd Arne. 2007. La guerre froide globale: le tiers-monde, les États-Unis et l'URSS (1945-1991). París: Payot.

Zanetti, Óscar. 2009. "Medio siglo de historiografía en Cuba: La impronta de la revolución”. Cuban Studies 40: 74-103.

Zardoya, Ruben. 1994. “Qué marxismo está en crisis?” En El derrumbe del modelo eurosoviético. La Habana: Editorial Félix Varela.

Zubok, Vladislav. 2007. A Failed Empire: the Soviet Union in the Cold War from Stalin to Gorbachev. Chapel Hill: University of North Carolina Press. EP 